\title{
Normal values of knee angle, intercondylar and intermalleolar distances in Nigerian children.
}

\author{
*Bade Omololu ${ }^{3}$, A. Tella ${ }^{1}$, S. O. Ogunlade ${ }^{3}$ A. A. Adeyemo', A. Adebisi', \\ T. O. Alonge ${ }^{3}$, S. A. Salawu ${ }^{3}$ and A. O. Akinpelu ${ }^{t}$ \\ Departments of Surgery ${ }^{3}$, Institute of Child Healt $h^{2}$ and Physiotherapy \\ College of Medicine, University of Ibadan.
}

\section{Summary}

There is little data on the range of variation of knce angle, intermalleolar and intercondylar distances in African children. Such measurements are needed to assist determining whether a child legs are normal or not.

Knee angle intermalleolar and intercondylar distances were measured in 2166 Nigerian children aged one year to $\mathbf{1 0}$ years to establish normal values for these measurements.

In the study we discovered that knees were maximally bowed at ages $1-3$ years and reduced to neutral of $0^{4}$ at age five (5 years) in girls and age seven (7) in boys. Both sexes had no bowing after age (7 years) in boys. Both sexes had no bowing after age of 7 years. The valgus angle was found to be constant at about 11" between ages 1-10 years in both sexes.

Mean intercondylar distance was $0.2 \mathrm{~cm}$ at 1 year of age and did not vary significantly at 10 years of age. The greatest intermalleolar distances of $2.5 \mathrm{~cm}$ and $2.2 \mathrm{~cm}$ were noted between the ages of 2 and 4 years. Normograms of these measurements are presented as diagnostic aids in clinical settings.

\section{Keywords: Knee angle, Anthropometry, Children, Nigeria}

\section{Résumé}

Il y a peu de données sur une gamme variée de l'angle de genous, intermalleole et distances intercondyles cchez des enfants nors.

Des mesurages pareils sont exigés pour pouvoir décider si les jambes d'un enfant sont normal ou non. L'angle du genou, intermalleole et distances intercondyles ont été méasurés chez 2166 enfants Nigerians âgés entre un a dix ans afin de décider des valeurs normales pour ces mesurages. Au cours de cet étude, nous avons remarqué que les genoux sont au grand maximum inclinés entre 1 à 3 ans et reduit au neutre de 0 à l'âge de cinq (5) ans chez les filles et à l'âge de sept (7) ans chez les garçons.

Après l'âge de 7 ans, ils n'y a plus d'inclinaison chez les deux sexes. L'angle valgus était remarqué d'entre constant à environ 11 entre l'âge $1-10$ ans chez les duex sexes. Distance intercondyle moyenne était $0,2 \mathrm{~cm}$ à $l^{\prime}$ âge d'un an et ne varie pas sensiblement à l'âge de 10 ans. Les distances intermalleoles les plus élevées de $2,5 \mathrm{~cm}$ et $2,2 \mathrm{~cm}$ ont été notés entre 2 et 4 ans. Les Normograms de ces mesurages sont ici présentés comme matériel diagnostic en ce qui concerne le cadre clinique.

\section{Introduction}

Bowlegs and knocked knees are common deformities seen in the Nigerian population, however, determining which of the deformities is pathological remains a problem in the population. With the impoverished state of the economy, one needs to be able to determine the normal limits of knee angle in Nige- rian children so as to be able to isolate early enough those children with pathological deformities.

There is no study to our knowledge either from the MEDLINE search or the internet which has addressed this peculiar problem in this environment or the West African Subregion.

Studies have been done in Whites ${ }^{1}$ and in the Chinese children ${ }^{2}$. A study in white children revealed the mean alignment of knee at age 2 years to be 5 degrees valgus \pm 10 degrees (2SD) and intermalieolar distance of $2.1 \mathrm{~cm}$ persisting until 7 years of age ${ }^{1}$. These variations in knee angle cause apprehension in parents ${ }^{3,4}$ but have been known to correct spontaneously in time ${ }^{5}$.

Several methods for assessing tibiofemoral angle have been investigated in Caucasians but radiological examination is expensive and exposes children to radiation ${ }^{1,2}$.

Clinical techniques include measurement of tibiofemoral angle and intermalleolar (IM) and intercondylar (IC) distances.

Establishing a range of normal values is of clinical importance in this environment as it provides the physician the means to determine whether knee angle is within normal limits.

Bowlegs and knock-knees are defined as knee angle within the normal range calculated as $2 \mathrm{SD}$ from the mean ${ }^{4}$. Valgus or varus beyond these limits is viewed as the threshold for concern suggesting the possibility of a pathologic condition. We wish to determine mean values and normal ranges for knee angle, and intercondylar or intermalleolar distance in Nigerian children.

\section{Materials and methods}

The children included in this study were from Lagos and Ibadan metropolis with age ranges between 1 year and 10 years. The children were recruited from day care centers, private nursery schools and public primary schools. Any child who had any obvious musculoskeletal disorders was excluded from the study.

Measurements of knee angle was done using the goniometer and intercondylar and intermalleolar distances were measured using a tape measure. These clinical methods are inexpensive, and they do not expose the children to radiation and correlate well with radiological measurements.

Children less than 2 years were examined supine in anatomic position with the medial condyles or malleoli touching and the pelvis square with hips and knees in maximal extension. Children aged 2-10 years were examined both in supine and standing with the feet together in anatomic position. For the measurement of femoral - tibia angle the goniometer was centered on the knce joint; while intermalleolar or intercondylar measurement was done by using a tape measure and determining the distance between the malleoli with the medial condyles touching or malleoli touching for intercondylar distance. Figs. A and B.

One arm of the goniometer was aligned to an imaginary line drawn from the anterior superior iliac spine to the middle of the patella, (femoral alignment) and the second arm was alinned 
Table 1 Means of Intermalleolar and Intercondylar Distances by age

\begin{tabular}{|c|c|c|c|}
\hline \multicolumn{2}{|c|}{ Age (years) } & $\begin{array}{l}\text { Intermalleolar } \\
\text { distance }\end{array}$ & $\begin{array}{l}\text { Intercondylar } \\
\text { distance }\end{array}$ \\
\hline \multirow[t]{3}{*}{1} & Mean & 1.47 & .78 \\
\hline & SD & 1.51 & 1.45 \\
\hline & $\mathbf{N}$ & 108 & 106 \\
\hline \multirow[t]{3}{*}{2} & Mean & 2.33 & 25 \\
\hline & SD & 1.68 & 1.00 \\
\hline & $\mathbf{N}$ & 163 & 163 \\
\hline \multirow[t]{3}{*}{3} & Meaan & 2.12 & .11 \\
\hline & SD & 1.65 & .60 \\
\hline & $\mathbf{N}$ & 200 & 200 \\
\hline \multirow[t]{3}{*}{4} & Mean & 2.02 & .15 \\
\hline & SD & 1.75 & .71 \\
\hline & $\mathbf{N}$ & 250 & 250 \\
\hline \multirow[t]{3}{*}{5} & Mean & 1.45 & .22 \\
\hline & SD & 1.62 & .59 \\
\hline & $\mathrm{N}$ & 227 & 227 \\
\hline \multirow[t]{3}{*}{6} & Mean & 1.63 & .34 \\
\hline & SD & 1.86 & 1.09 \\
\hline & $\mathbf{N}$ & 270 & 270 \\
\hline \multirow[t]{3}{*}{7} & Mean & .86 & .10 \\
\hline & SD & 1.29 & .43 \\
\hline & $\mathbf{N}$ & 222 & 222 \\
\hline \multirow[t]{3}{*}{8} & Mean & .73 & .22 \\
\hline & SD & 1.14 & .61 \\
\hline & $\mathbf{N}$ & 242 & 242 \\
\hline \multirow[t]{3}{*}{9} & Mean & .81 & .16 \\
\hline & SD & 1.17 & .64 \\
\hline & $\mathbf{N}$ & 260 & 260 \\
\hline \multirow[t]{3}{*}{10} & Mean & 1.00 & .10 \\
\hline & $\mathrm{SD}$ & 1.38 & .43 \\
\hline & $\mathbf{N}$ & 224 & 224 \\
\hline \multirow[t]{3}{*}{ Total } & Mean & 1.40 & .22 \\
\hline & SD & 1.62 & .78 \\
\hline & $\mathrm{N}$ & 2166 & 2166 \\
\hline
\end{tabular}

to a line joining the middle of the patella to the middle of the ankle (centre point between medial and lateral malleoli) tibial alignment). The angle sustained between the femoral shaft and the tibia shaft on the goniometer was recorded as the tibiofemoral angle. Figs $B$ and $C$.

The data were analysed using the statistical package for the social sciences (SPSS) version 10 for windows. Means and

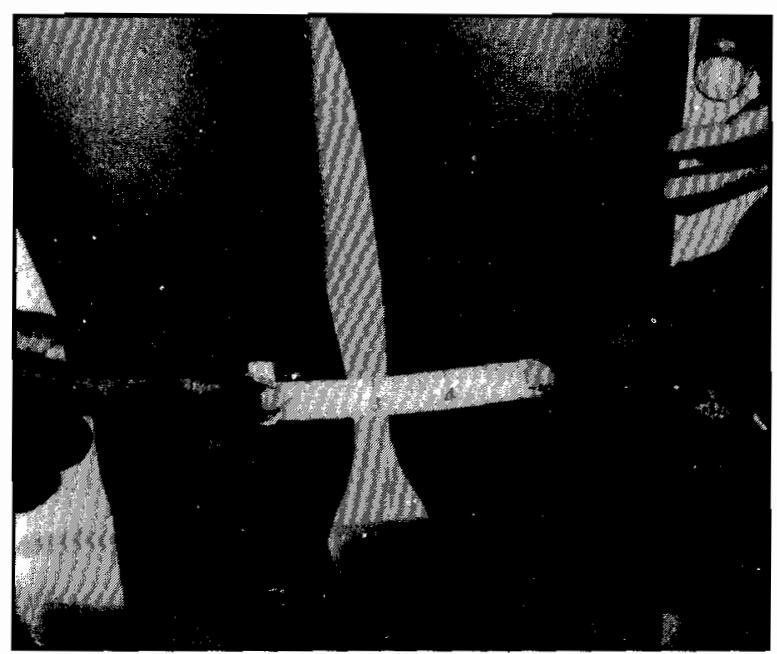

Fig. A Measurement of intercondylar distance in a normal leg. standard deviations of each measurement were romputed by one-year age intervals. Analysis of variance (ANCIVA) showed that age was a significant covariate of the measureraents but sex was not. Therefore, the means and standard deviations (SD) were presented for the sexes combined. Nornlograms for intermalleolar and intercondylar distances were crawrı by fitting linear regression models with age up to the cubic polynomial, retaining terms that were significant at the $p: 0.05$ level.

\section{Results}

A total number of 2166 children were studic $d$, with boys comprising $49.7 \%$ and girls $51.3 \%$. Each one-year age interval

Table 2 Mean varus angle in Boys and Girls

\begin{tabular}{llll}
\hline Age - Boys & $\begin{array}{l}\text { Varus angle } \\
\text { mean }\end{array}$ & Age - Girls Valus Angle \\
me a n \\
1 year & 0.60 & 1 year & 1.95 \\
2 years & 1.6 & 2 years & 1.47 \\
3 years & 0.27 & 3 years & 0.87 \\
4 years & 0.20 & 4 years & 0.31 \\
5 years & 0.19 & 5 years & 0.0 \\
6 years & 0.29 & 6 years & 0.0 \\
7 years & 0.0 & 7 years & 0.0 \\
8 years & 0.0 & 8 years & 0.0 \\
9 years & 0.05 & 9 years & 0.0 \\
10 years & 0.0 & 10 years & 0.0 \\
\hline
\end{tabular}

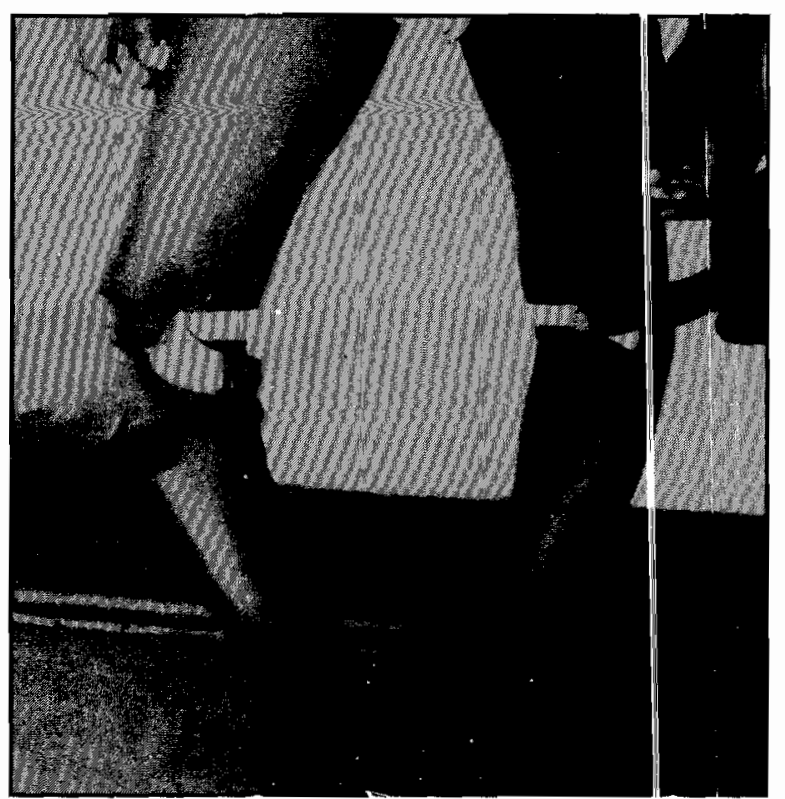

Fig. B measurement of intercondylar distance in a petient with bilateral tibia vara (bowlegs).

from 1 year to 10 years had at least 100 children (ser Table 1).

\section{IC and IM distances}

Measurement of IM distance showed variations from extreme varus at 12 months of age to maximum valgu; between the ages of seven and nine years of age. Greatest IM distances of $2.5 \mathrm{~cm}$ and $2.2 \mathrm{~cm}$ were noted between the ages $0 !^{\prime} 2$ and 4 years. Table 1 .

Mean IC distance was $0.2 \mathrm{~cm}$ at one year of ag', and did 
Table 3 Knee angle in the standing position

\begin{tabular}{|c|c|c|c|c|c|}
\hline \multicolumn{2}{|c|}{$\begin{array}{l}\text { Age } \\
\text { (years) }\end{array}$} & $\begin{array}{l}\text { Left } \\
\text { varum }\end{array}$ & $\begin{array}{l}\text { Right } \\
\text { varum }\end{array}$ & $\begin{array}{l}\text { Left } \\
\text { valgum }\end{array}$ & $\begin{array}{l}\text { Right } \\
\text { valgum }\end{array}$ \\
\hline \multirow[t]{3}{*}{1} & Mean & 1.4 & 1.5 & 11.1 & 11.3 \\
\hline & SD & 5.0 & 5.3 & 5.8 & 5.9 \\
\hline & $\mathrm{N}$ & 108 & 108 & 108 & 108 \\
\hline \multirow[t]{3}{*}{2} & Mean & 1.6 & 1.7 & 12.5 & 12.5 \\
\hline & SD & 4.1 & 4.0 & 7.1 & 7.0 \\
\hline & $N$ & 163 & 163 & 163 & 163 \\
\hline \multirow[t]{3}{*}{3} & Mean & .6 & .6 & 14.1 & 14.2 \\
\hline & SD & 2.4 & 2.3 & 5.8 & 5.6 \\
\hline & $\mathrm{N}$ & 200 & 200 & 200 & 200 \\
\hline \multirow[t]{3}{*}{4.} & Mean & .2 & .2 & 11.1 & 11.0 \\
\hline & SD & 1.1 & 1.0 & 5.5 & 6.0 \\
\hline & $\mathrm{N}$ & 250 & 250 & 250 & 250 \\
\hline \multirow[t]{3}{*}{5} & Mean & .1 & .2 & 10.0 & 9.7 \\
\hline & SD & 1.2 & 1.4 & 4.9 & 5.3 \\
\hline & $\mathrm{N}$ & 227 & 227 & 227 & 227 \\
\hline \multirow[t]{3}{*}{6} & Mean & .3 & .2 & 9.2 & 9.0 \\
\hline & SD & 1.9 & 1.9 & 3.9 & 3.9 \\
\hline & $\mathrm{N}$ & 270 & 270 & 270 & 270 \\
\hline \multirow[t]{3}{*}{7} & Mean & .1 & .0 & 10.9 & 11.0 \\
\hline & SD & .7 & .5 & 3.0 & 2.9 \\
\hline & $\mathrm{N}$ & 222 & 222 & 222 & 222 \\
\hline \multirow[t]{3}{*}{8} & Mean & .0 & .0 & 10.1 & 10.1 \\
\hline & SD & .0 & .0 & 3.0 & 2.9 \\
\hline & $\mathrm{N}$ & 242 & 242 & 242 & 242 \\
\hline \multirow[t]{3}{*}{9} & Mean & .0 & .0 & 10.5 & 10.4 \\
\hline & SD & .3 & .3 & 3.1 & 3.0 \\
\hline & $\mathbf{N}$ & 260 & 260 & 260 & 260 \\
\hline \multirow[t]{3}{*}{10} & Mean & .0 & .0 & 10.5 & 10.5 \\
\hline & SD & .5 & .0 & 2.9 & 2.9 \\
\hline & $\mathrm{N}$ & 224 & 224 & 224 & 224 \\
\hline \multirow[t]{3}{*}{ Total } & Mean & .3 & .3 & 10.9 & 10.8 \\
\hline & SD & 2.0 & 2.0 & 4.7 & 4.8 \\
\hline & $\mathrm{N}$ & 2166 & 2166 & 2166 & 2166 \\
\hline
\end{tabular}

not vary significantly at 10 years of age for males. Table 2 However, the mean IC distances for females at 1 year of $1.2 \mathrm{~cm}$

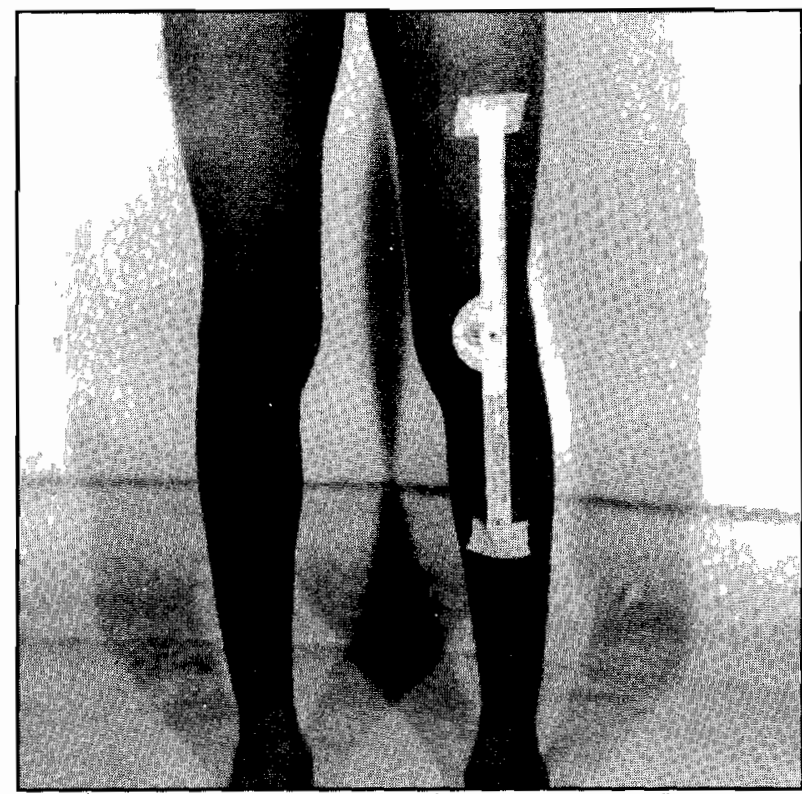

Fig. $\mathrm{C} U$ se of a gonimeter to measure the tibiofemoral angle (Knee angle).
Table 4 Knee angle in the supine position

\begin{tabular}{|c|c|c|c|c|c|}
\hline \multicolumn{2}{|c|}{$\begin{array}{l}\text { Age } \\
\text { (years) }\end{array}$} & $\begin{array}{l}\text { Left } \\
\text { varum }\end{array}$ & $\begin{array}{l}\text { Right } \\
\text { varum } \\
\text { (supine) }\end{array}$ & $\begin{array}{l}\text { Left } \\
\text { valgum } \\
\text { (sunine) }\end{array}$ & $\begin{array}{l}\text { Right } \\
\text { valgum } \\
\text { (supine) }\end{array}$ \\
\hline \multirow[t]{3}{*}{1} & Mean & 1.4 & 1.4 & 10.9 & 10.8 \\
\hline & SD & 4.8 & 5.0 & 5.7 & 5.9 \\
\hline & $\mathbf{N}$ & 108 & 108 & 108 & 108 \\
\hline \multirow[t]{3}{*}{2} & Mean & 1.6 & 1.5 & 12.3 & 12.2 \\
\hline & SD & 3.6 & 3.5 & 6.9 & 6.9 \\
\hline & $\mathrm{N}$ & 163 & 163 & 163 & 163 \\
\hline \multirow[t]{3}{*}{3} & Mean & .6 & .6 & 13.9 & 13.9 \\
\hline & $S D$ & 2.2 & 2.1 & 5.4 & 5.4 \\
\hline & $N$ & 200 & 200 & 200 & 200 \\
\hline \multirow[t]{3}{*}{4.} & Mean & .3 & .2 & 12.0 & 11.9 \\
\hline & SD & 1.6 & 1.5 & 4.5 & 4.7 \\
\hline & $N$ & 250 & 250 & 250 & 250 \\
\hline \multirow[t]{3}{*}{5} & Mean & .1 & .1 & 10.8 & 10.8 \\
\hline & SD & 1.1 & 1.1 & 3.9 & 4.0 \\
\hline & $N$ & 227 & 227 & 227 & 227 \\
\hline \multirow[t]{3}{*}{6} & Mean & .2 & .2 & 9.2 & 9.4 \\
\hline & SD & 1.9 & 1.7 & 3.4 & 3.3 \\
\hline & $N$ & 270 & 270 & 270 & 270 \\
\hline \multirow[t]{3}{*}{7} & Mean & .1 & .0 & 10.6 & 10.6 \\
\hline & SD & .6 & .4 & 3.1 & 3.0 \\
\hline & $\mathbf{N}$ & 222 & 222 & 222 & 222 \\
\hline \multirow[t]{3}{*}{8} & Mean & .0 & .0 & 9.8 & 9.8 \\
\hline & SD & .0 & .0 & 3.0 & 2.9 \\
\hline & $\mathbf{N}$ & 242 & 242 & 242 & 242 \\
\hline \multirow[t]{3}{*}{9} & Mean & .0 & .0 & 10.1 & 10.2 \\
\hline & SD & .3 & .3 & 3.1 & 3.1 \\
\hline & $\mathrm{N}$ & 260 & 260 & 260 & 260 \\
\hline \multirow[t]{3}{*}{10} & Mean & .0 & .0 & 10.1 & 10.1 \\
\hline & SD & .0 & .0 & 3.1 & 3.0 \\
\hline & $\mathbf{N}$ & 224 & 224 & 224 & 224 \\
\hline \multirow[t]{3}{*}{ Total } & Mean & .3 & .3 & 10.9 & 10.9 \\
\hline & SD & 1.9 & 1.9 & 4.4 & 4.4 \\
\hline & $\mathrm{N}$ & 2166 & 2166 & 2166 & 2166 \\
\hline
\end{tabular}

and decreasing to $0 \mathrm{~cm}$ at 10 years of age was not statistically significant.

\section{Genu varus: Genu valgus}

We found in this study that most children had a maximum bowing at ages $1-3$ years and this reduced to neutral or $0^{\circ}$ at the age of 5 years in girls and age 7 years in males. All patients had no bowing i.e. varus angle of $0^{\circ}$ from the age of seven upwards. Table 2.

The valgus angle seems to remain almost the same throughout the ages $1-10$ years of age with a mean angle of about $11^{\circ}$.

The mean values, normal ranges and (SD) of valgus and varus angles in the standing position and supine position are shown in Tables 3 and 4 respectively.

\section{Discussion}

The knee angles in White children are well documented", so also are those of Chinese children ${ }^{2}$. There has been no study in the West African Sub--region that has reported the knee angle in black Africans. Knee angle development in children has been thoroughly investigated by so many authors using various methods but no method has shown any significant difference between boys and girls $1,2,3,4,5,6,7$.

Studies conducted observed that in White American children that knee angle was significantly different $P<0.05$ ) only in 4 years old male and female subjects. However, in contrast to 
the above there was marked difference in knee angle in Nigerian children with maximal bowing at 1-3 years and reducing to neutral of $0^{\circ}$ at the age of 5 years in girls and 7 years in boys. All children were noted to have no bowing i.e. varus angle of $0_{0}$ from the age of seven ( 7 years) upwards.

Salenius and $V_{a n k a}{ }^{3}$, reported mean varus of $16.5^{\circ}$ at birth decreasing to $10-12^{\circ}$ at 1 year with greatest mean valgus of $12^{\circ}$ evident at 3 years of age in White American children.

The mean valgus angle of $12^{\circ}$ in the Vankas study compared well with the mean valgus angle of $11^{\circ}$ in our own study. However, the varus angle reported by Vanka differed with that reported in our study ( $>2^{\circ}$ at age of 1 year) as the varus angle is less than $2^{\circ}$ in 1 year old in this environment and maximal bowing or varus occurring between the ages of 1-3 years.

The Chinese study ${ }^{2}$ demonstrated greatest mean tibiofemoral angle of $8^{\circ}$ valgus at 3.5 years and this only compared with the age of 6 years in this environment with valgus angle of $12^{\circ}$ at age of 3.5 years.

The Chinese study concluded that normal children aged between 3 and 11 years exhibit a significant degree of varus $\leq 5^{\circ}$ in contrast to our study where varus angle approached $0^{\circ}$ at age 5 in girls and age 7 in boys. The discrepancy between the mean value reported in American children, the Chinese children and the Nigerian children could only result from racial differences.

Our new finding suggests that varus angle differ according to gender between the ages of 3 and 7 years whereas it remains constant or same after the age of 7 years in black African children. The valgus angle does not seem to differ much with gender. Our study.has established data for the varus/valgus profile of the legs in normal children between the ages of 1 'car and 10 years in Nigeria. For children showing greater value: than these genu varum or valgum require more evaluation, for $p$ athological condition.

\section{References}

1. Cheng JCY, Chan PS, Chiang SC, Hui PW: Angul ar rotational profile of the lower limb on 2630 Chinese childre i. J. Pediatr Orthop. 1991; 11: 154-61.

2. Engel GM, Stahelli LT: The National history of torsion, other factors influencing gait, in childhood. A study of angle, of gait tibia torsion, knee angle, hip rotation, deve lopment of the arch in normal children. Clin. Orth. 1974; 95: $12-17$.

3. Salenius P, Vanka E. The development of the tibiofemoral angle in children. JBJS Am. 1975; 57: 259 - 64.

4. Sharrard WJW: Knock-knees and bowlegs. Br. Mrd. J. 1976; $826-7$.

5. Sherman M. Physiological bowing of the legs. Scuth Med. J $1960 ; 53: 830-6$.

6. Greene WB: Genu varum and genu valgum in $c$ ildren. In Schafer $M$. ed. Instructional course lectures $43 . R$, semont $K$. American Academy of orthopaedic Surgeons; 1'194; 151 159.

7. Levine AM, Drennan JC: Physiological bowing anc tibia vera; the metaphyseal - diaphyseal angle in the mcas irement of bowleg deformities JBJS 1982 64A: $1158-1163$ 